\title{
Effects of proteinase inhibitors on preimplantation embryos in the rat
}

\author{
S. Ichikawa, T. Shibata, Y. Takehara, H. Tamada, K. Oda* and S. Murao* \\ Laboratory of Animal Reproduction and * Laboratory of Applied Microbiology, \\ College of Agriculture, University of Osaka Prefecture, Sakai City, Osaka 591, Japan
}

\begin{abstract}
Summary. Proteinase inhibitors of microbial origin were injected into the uterine horns of mated rats at 14:00 h on Day 5 of pregnancy (spermatozoa in vaginal smear = Day 1), and 5 or $6 \mathrm{~h}$ later the embryos were flushed from the horns and examined. Chymostatin and $\alpha$-MAPI, inhibitors of chymotrypsin-like serine proteinase and thiol proteinases, as well as thiolstatin, an inhibitor of thiol proteinases, significantly inhibited embryo growth. The inhibitory activity of $\alpha$-MAPI on embryonic growth was distinctly greater than that of thiolstatin, although the $\mathrm{ID}_{50}$ values of the two inhibitors to papain are similar. Antipain and leupeptin which are inhibitors of trypsin-like and thiol proteinases, and talopeptin, an inhibitor of metal proteinases, significantly interrupted the removal of the zona pellucida from expanding blastocysts. These results suggest that (1) a chymotrypsin-like proteinase seems to be important to the growth of the embryo, (2) a thiol proteinase may participate in embryonic growth, and (3) a trypsin-like proteinase and a metal proteinase are likely to participate in zonalysis.
\end{abstract}

\section{Introduction}

Proteolytic activity has been recognized in uterine secretions and in trophoblast at about the time of preimplantation in many mammals. The involvement of proteinases in lysis of the zona pellucida and in embryonal attachment to the uterine epithelium have also been suggested (Mintz, 1972; Morton, 1977; Denker, 1977). However, the identity of the participating proteolytic enzymes and their physiological roles are virtually unknown.

The present study was undertaken to obtain information on proteinases which may participate in the sequential events during the hours before implantation of rat embryos.

\section{Materials and Methods}

Animals. Sprague-Dawley female rats showing regular 4-day cycles and weighing 200-300 g were used. They were housed at $24 \pm 1^{\circ} \mathrm{C}$ in a lighting schedule of $14 \mathrm{~h}$ light $(05: 00-19: 00 \mathrm{~h})$. All females were induced to superovulate by a subcutaneous injection of a saline $(9 \mathrm{~g} \mathrm{NaCl} / \mathrm{l})$ extract of a single rat pituitary gland at $13: 00-14: 00 \mathrm{~h}$ on the first day of dioestrus (Sameshima, Taya, Sasamoto \& Etoh, 1982). The extracted pituitary glands were taken from 35-45-day-old male rats. The females were caged with males in the evening 2 days after the injection; mating was confirmed by the presence of spermatozoa in the vaginal smear taken the next morning. This was designated Day 1 of pregnancy.

Injection of proteinase inhibitors. Proteinase inhibitors were injected into the uterus under ether anaesthesia at $14: 00 \mathrm{~h}$ on Day 5 of pregnancy, before implantation. Since the intrauterine injection of $20 \mu \mathrm{l}$ saline $(9 \mathrm{~g} \mathrm{NaCl} / 1)$ resulted in a drastic decrease in the number of recoverable embryos, a cotton tampon saturated with a $2 \%$ aqueous solution of lidocain hydrochloride (Xylocain: Fujisawa 
Table 1. Effects of an intrauterine injection of $20 \mu \mathrm{l}$ saline at $14: 00$ $h$ on Day 5 of pregnancy and of local anaesthesia at the time of injection on the recovery of embryos in superovulated pregnant rats

\begin{tabular}{lccc}
\hline Injection & $\begin{array}{c}\text { Local } \\
\text { anaesthesia }\end{array}$ & $\begin{array}{c}\text { No. of } \\
\text { rats }\end{array}$ & $\begin{array}{c}\text { Mean } \pm \text { s.e.m. } \\
\text { no. of embryos } \\
\text { recovered }\end{array}$ \\
\hline None & - & 4 & $18.0 \pm 1 \cdot 2^{\mathrm{a}}$ \\
Saline & - & 4 & $1 \cdot 8 \pm 0.3^{\mathrm{b}}$ \\
Saline & + & 7 & $9.9 \pm 1 \cdot 3^{\mathrm{c}}$ \\
\hline * Embryos were collected 5 h after injection. \\
Values with different superscripts were significantly different, \\
$P<0.01$.
\end{tabular}

Pharmaceutical Co., Osaka) was placed in the vagina for $10 \mathrm{~min}$ immediately before the injection to block uterine contractions resulting from the injection. This procedure improved the recovery of embryos (Table 1). The vagina was opened by the insertion of an ear speculum, and $20 \mu \mathrm{l}$ of the inhibitor solution was injected into each uterine horn through the cervix by means of a $0.25 \mathrm{ml}$ syringe with a blunt-ended 23-gauge needle. When $20 \mu$ lof dye solution were injected, the dye immediately dispersed throughout the uterine horn, indicating that this volume is sufficient to contact all embryos in the horn.

Proteinase inhibitors. Leupeptin, antipain, $\alpha$-MAPI and chymostatin, which are inhibitors of serine and thiol proteinases (EC 3.4.21 and EC 3.4.22, respectively); thiolstatin, an inhibitor of thiol proteinases; talopeptin, an inhibitor of metal proteinases (EC 3.4.24); and Ac-pepstatin, an inhibitor of acid proteinases (EC 3.4.23) were used in this study. Sources of the inhibitors and their inhibitory spectra were as described by Ichikawa, Morioka, Ohta, Oda \& Murao (1983) and Ichikawa et al. (1984). Antipain, $\alpha$-MAPI and chymostatin were first dissolved in dimethylsulphoxide (DMSO: Sigma) and then diluted with saline to the concentration of $5 \%$ DMSO. The remaining inhibitors were dissolved in saline $(9 \mathrm{~g} \mathrm{NaCl} / \mathrm{l})$.

Collection and classification of embryos. Rats were killed by an overdose of ether 5 or $6 \mathrm{~h}$ after the injection of the proteinase inhibitor. The embryos were flushed from the excised uterus with $0.4 \mathrm{ml}$ phosphate-buffered saline ( $\mathrm{pH} 7 \cdot 2$ ) into a watch glass, and examined under a microscope at $\times 100$.

Embryos were classified as follows: (a) morula, (b) young blastocyst (blastocoele occupied less than one-half of the volume of the egg, and the boundary between trophoblast and inner cell mass was not clear), (c) mature blastocyst (clearly demarcated trophoblast and inner cell mass), (d) expanding blastocyst (blastocyst was expanded and the zona was thin), and (e) exposed blastocyst which included the hatching blastocyst and the zona-free blastocyst. Early blastocysts included morulae and young and mature blastocysts. Embryonic development was evaluated by comparing the number of early blastocysts with that of control rats and by comparing the distribution pattern of blastocysts with that of the controls at various times on Day 5 of pregnancy. The inhibitory activity of proteinase inhibitors on removal of the zona was evaluated by the rate of zona loss which was defined as the percentage of exposed blastocysts of the sum of expanding and exposed blastocysts. The differences between the numbers of embryos were analysed by the $\chi^{2}$ test or by Fisher's exact probability test; the differences between the mean numbers of blastocysts were analysed by Student's $t$ test.

\section{Results}

Effects of an intrauterine injection of medium solutions on embryonic development

To determine the times when loss of the zona pellucida from the blastocysts begins and is completed, normal pregnant rats and superovulated pregnant rats were killed between 14:00 and 
Table 2. Stages of developing embryos between 14:00 and 20:00 h on Day 5 of pregnancy in superovulated rats and in rats injected into each uterine horn with saline or dimethylsulphoxide at $14: 00 \mathrm{~h}$

\begin{tabular}{|c|c|c|c|c|c|c|c|c|c|}
\hline \multirow[b]{2}{*}{ Treatment } & \multirow[b]{2}{*}{$\begin{array}{l}\text { Time at } \\
\text { observation } \\
\text { (h) }\end{array}$} & \multicolumn{7}{|c|}{ Nos of embryos* } & \multirow[b]{2}{*}{$\begin{array}{l}\text { Rate of } \\
\text { zona loss } \\
\left.\frac{\mathrm{e}}{\mathrm{d}+\mathrm{e}} \times 100\right)\end{array}$} \\
\hline & & Total & $\begin{array}{l}\text { Morula } \\
\text { (a) }\end{array}$ & $\begin{array}{l}\text { Young } \\
\text { blasto- } \\
\text { cyst } \\
\text { (b) }\end{array}$ & $\begin{array}{l}\text { Mature } \\
\text { blasto- } \\
\text { cyst } \\
\text { (c) }\end{array}$ & $\begin{array}{c}\text { Early } \\
\text { blasto- } \\
\text { cyst } \\
(a+b+c)\end{array}$ & $\begin{array}{l}\text { Expanding } \\
\text { blasto- } \\
\text { cyst } \\
\text { (d) }\end{array}$ & $\begin{array}{l}\text { Exposed } \\
\text { blasto- } \\
\text { cyst } \\
\text { (e) }\end{array}$ & \\
\hline \multirow[t]{7}{*}{ None } & $14: 00$ & 98 & 4 & 26 & 44 & 74 & 24 & 0 & 0 \\
\hline & $15: 00$ & 78 & 1 & 8 & 35 & 44 & 28 & 6 & 19 \\
\hline & $16: 00$ & 63 & 0 & 8 & 32 & 40 & 11 & 12 & 51 \\
\hline & $17: 00$ & 87 & 5 & 10 & 18 & 33 & 18 & 36 & 66 \\
\hline & $18: 00$ & 88 & 0 & 7 & 29 & 36 & 13 & 39 & 75 \\
\hline & $19: 00$ & 86 & 0 & 0 & 0 & 0 & 0 & 86 & 100 \\
\hline & $20: 00$ & 89 & 0 & 0 & 0 & 0 & 0 & 89 & 100 \\
\hline \multirow{2}{*}{$0.9 \%$ saline } & $19: 00$ & 47 & 0 & 0 & 21 & 21 & 18 & 8 & 31 \\
\hline & $20: 00$ & 84 & 0 & 0 & 12 & 12 & 14 & 58 & 81 \\
\hline \multirow[t]{3}{*}{$5 \%$ DMSO } & $18: 00$ & 91 & 2 & 10 & 35 & 47 & 33 & 11 & 25 \\
\hline & $19: 00$ & 80 & 0 & 0 & 19 & 19 & 10 & 51 & 84 \\
\hline & $20: 00$ & 80 & 0 & 0 & 0 & 0 & 0 & 80 & 100 \\
\hline
\end{tabular}

* Degenerate embryos were not considered.

20:00 h on Day 5 of pregnancy, and their embryos were examined. In the normal pregnant rats, exposure of blastocysts began at $17: 00 \mathrm{~h}$. From this time onward the number of exposed blastocysts increased. Zona loss was complete in all blastocysts by $22: 00 \mathrm{~h}$ (data not presented). In superovulated rats, as shown in Table 2, the time of zona loss began at 15:00 $\mathrm{h}$ and was completed by $19: 00 \mathrm{~h}$. An intrauterine injection of $20 \mu \mathrm{l}$ medium given at 14:00 h delayed the process of blastocyst development. Zona loss in $>80 \%$ of treated blastocysts was attained by $20: 00 \mathrm{~h}$ in saline-injected rats and by 19:00 h in DMSO-injected rats (Table 2). Blastocysts with a ruptured zona pellucida or blastocysts extruding through a rupture were rarely observed, indicating that the process of zona loss proceeded quickly.

\section{Effects of proteinase inhibitors on rat blastocysts}

Blastocysts treated with inhibitors were examined at 19:00 h (5\% DMSO medium) and $20: 00 \mathrm{~h}$ (saline medium). By these times $80 \%$ of control blastocysts had hatched. Results are shown in Table 3. $\alpha$-MAPI, chymostatin and thiolstatin significantly suppressed embryonic development; numbers of early blastocysts were significantly greater than that of controls. At 19:00 h the distribution of blastocysts treated with $0.16 \mathrm{mM}-\alpha$-MAPI corresponded to the development of untreated blastocysts at 14:00 h and 15:00 h (Table 2), indicating that embryonic development was almost completely blocked by $0.16 \mathrm{mM}-\alpha$-MAPI. Chymostatin at $0.16 \mathrm{~mm}$ also delayed development of embryos to a degree similar to that of $0.16 \mathrm{mM}-\alpha-\mathrm{MAPI}$, although 22 of these embryos $(30 \%)$ had lost the zona pellucida. Blastocysts treated with 0.08 or $0.04 \mathrm{mM}-\alpha-$ MAPI displayed a developmental pattern comparable to that of DMSO-treated control blastocysts at $18: 00 \mathrm{~h}$. The distribution pattern of blastocysts treated with $1.6 \mathrm{mM}$-thiolstatin was nearly equivalent to that seen at $19: 00 \mathrm{~h}$ in saline-treated controls. These observations suggest that $0.06 \mathrm{mM}-\alpha-\mathrm{MAPI}$ and $1.6 \mathrm{mM}$-thiolstatin delayed blastocyst growth to the same degree; therefore, the growth-inhibiting activity of $\alpha$-MAPI is distinctly greater than that of thiolstatin.

In rats treated with $1.6 \mathrm{~mm}$-antipain, leupeptin and talopeptin, developmental patterns of early blastocysts were not significantly different from those of the corresponding controls. However, the rates of zona-loss from the blastocysts were significantly less than those of the controls. The results 
Table 3. Developing stages of embryos at $19: 00$ and 20:00 h on Day 5 of pregnancy in rats treated at 14:00 $\mathrm{h}$ with an intrauterine injection of proteinase inhibitors

\begin{tabular}{|c|c|c|c|c|c|c|c|c|c|}
\hline \multirow[b]{2}{*}{ Inhibitor } & \multirow[b]{2}{*}{$\begin{array}{l}\text { Concn. } \\
\text { (mM) }\end{array}$} & \multirow[b]{2}{*}{$\begin{array}{l}\text { No. } \\
\text { of } \\
\text { rats }\end{array}$} & \multicolumn{6}{|c|}{ Nos of embryos } & \multirow[b]{2}{*}{$\begin{array}{c}\text { Rate of } \\
\text { zona loss } \\
\left(\frac{c}{b+c} \times 100\right)\end{array}$} \\
\hline & & & $\begin{array}{c}\text { Total } \\
(a+b+c)\end{array}$ & $\begin{array}{c}\text { Mean } \pm \text { s.e.m. } \\
\text { per rat }\end{array}$ & Morula & $\begin{array}{l}\text { Early } \\
\text { blasto- } \\
\text { cyst } \\
\text { (a) }\end{array}$ & $\begin{array}{l}\text { Expanding } \\
\text { blasto- } \\
\text { cyst } \\
\text { (b) }\end{array}$ & $\begin{array}{l}\text { Exposed } \\
\text { blasto- } \\
\text { cyst } \\
\text { (c) }\end{array}$ & \\
\hline \multicolumn{10}{|c|}{ Inhibitors dissolved in $5 \%$ DMSO } \\
\hline \multirow{4}{*}{$\begin{array}{l}\text { None (DMSO } \\
\alpha \text {-MAPI }\end{array}$} & control) & 7 & 74 & \multirow{2}{*}{$\begin{array}{r}10.4 \pm 0.7 \\
8.9+1.7\end{array}$} & 1 & & 9 & 44 & 83 \\
\hline & 0.16 & 8 & 71 & & 5 & & 35 & \multirow[t]{2}{*}{$\mathbf{0}$} & $0^{*}$ \\
\hline & 0.08 & 7 & 84 & $12 \cdot 0 \pm 1 \cdot 0$ & 2 & $\begin{array}{l}36^{*} \\
34\end{array}$ & 42 & & $16^{*}$ \\
\hline & 0.04 & 7 & 78 & $11 \cdot 6 \pm 1 \cdot 0$ & 0 & 34 & 30 & 14 & $32^{*}$ \\
\hline \multirow{2}{*}{$\begin{array}{l}\text { Antipain } \\
\text { Chymostatin }\end{array}$} & \multirow{2}{*}{$\begin{array}{l}1 \cdot 6 \\
0 \cdot 16\end{array}$} & 9 & 94 & $10.4 \pm 0.7$ & 0 & \multirow{2}{*}{$\begin{array}{l}23 \\
41^{*}\end{array}$} & 61 & \multirow{2}{*}{$\begin{array}{l}10 \\
22\end{array}$} & $14^{*}$ \\
\hline & & 8 & 73 & $9 \cdot 1 \pm 1 \cdot 4$ & 10 & & 10 & & 69 \\
\hline \multicolumn{10}{|c|}{ Inhibitors dissolved in saline } \\
\hline \multicolumn{2}{|c|}{ None (saline control) } & 7 & 69 & $9 \cdot 9 \pm 1 \cdot 3$ & 0 & 11 & 10 & 48 & 83 \\
\hline Thiolstatin & 1.6 & 7 & 69 & $9.9 \pm 0.9$ & 3 & $31^{*}$ & 24 & 14 & $37^{*}$ \\
\hline Leupeptin & 1.6 & 7 & 62 & $8.9 \pm 0.8$ & 1 & 17 & 28 & 17 & $38^{*}$ \\
\hline \multirow[t]{2}{*}{ Talopeptin } & 1.6 & 7 & 59 & $8.4 \pm 1.6$ & 0 & 17 & 34 & 8 & $19^{*}$ \\
\hline & 0.04 & 7 & 71 & $10.1 \pm 0.9$ & 0 & 14 & 18 & 39 & 68 \\
\hline Ac-pepstatin & 1.6 & 7 & 75 & $10.9 \pm 1.5$ & 0 & 14 & 15 & 46 & 75 \\
\hline
\end{tabular}

$\dagger$ Includes morulae and young and mature blastocysts.

$* P<0.01$ compared to the corresponding controls.

indicate that these inhibitors did not affect development of the blastocysts but did suppress zonalysis. Only pepstatin had no effect at all on blastocyst development at a concentration of $1.6 \mathrm{~mm}$.

\section{Discussion}

Chymostatin and $\alpha$-MAPI, both of which are strong inhibitors of chymotrypsin (EC 3.4.21.1) and thiol proteinases, strongly inhibited the growth of the rat embryo. The inhibitory activities of chymostatin and $\alpha$-MAPI were distinctly greater than that of thiolstatin, although the $50 \%$ inhibition concentrations ( ID $_{50}$ ) of $\alpha$-MAPI and thiolstatin against papain (EC 3.4.22.2) are almost the same (Ichikawa et al., 1984). These findings suggest that a chymotrypsin-like proteinase is required for embryonic growth and that a thiol proteinase also participates in the process to a lesser degree. However, it cannot be excluded that the different effects of $\alpha$-MAPI and thiolstatin on embryonic growth might be produced by a differential effect of the inhibitors on lysosomal enzymes rather than on chymotrypsin. The mitotic action of trypsin (EC 3.4.21.4) and chymotrypsin on normal cells has been reported by Mazzei, Novi \& Bazzi (1966). Treatment with trypsin or pronase stimulated the development of mouse blastocysts in vitro (Pienkowski, Solter \& Koprowski, 1974; Konwinski, Solter \& Koprowski, 1978). Trypsin caused the outgrowth of rabbit embryos, and trypsin inhibitors inhibited outgrowth (Kane, 1983). In the present study, leupeptin and antipain, which are trypsin inhibitors, had no effect on the growth of rat blastocysts. Therefore, in the rat, a chymotrypsin-like proteinase, but not trypsin, is likely to be the proteinase required for growth of the blastocysts. Dabich \& Andary $(1974,1976)$ and Hoversland \& Weitlauf $(1978,1981)$ recognized a chymotrypsin-like proteinase in mouse blastocysts and uterine fluid and suggested that it may be involved in the initiation of implantation.

The mechanism involved in erosion of the zona pellucida is still uncertain. According to 
morphological observations, physical forces resulting from the distension of the blastocoele and the pulsatile activity of the blastocyst (hatching mechanism) seem to be the major causes of zona pellucida erosion (Fléchon \& Renard, 1978; Massip \& Mulnard, 1980). On the other hand, McLaren (1970) suggested that a lytic factor produced by the oestrogen-sensitized uterus may be responsible for loss of the zona of the mouse blastocyst. Pinsker, Sacco \& Mintz (1974) also found increased proteolytic activity in mouse uterine fluid at the time of implantation. Furthermore, proteinase activity has been observed in the trophoblast, which suggested proteinase participation in zona lysis in the guinea-pig and rabbit (Owers \& Blandau, 1968; Denker, 1972, 1977). However, the effects of proteinases on the removal of the zona pellucida from the ovum in vitro are variable, as seen by different workers. For example, for mouse eggs, Gwatkin (1964) reported that papain and ficin (EC 3.4.22.3) were effective but trypsin and $\alpha$-chymotrypsin were ineffective; while Smithberg (1953) reported that trypsin and chymotrypsin were effective, and papain was ineffective. Mintz (1962) included trypsin, chymotrypsin and ficin in the list of effective enzymes and considered collagenase and elastase (EC 3.4.21.11) ineffective. In the rat, an oestrogen-induced endopeptidase of uterine origin has been recognized ; this peptidase caused lysis of the zona pellucida of unfertilized rat eggs, but had no effect on fertilized eggs (Rosenfeld \& Joshi, 1981). Up to now no proteinase activity has been found in the blastocyst of the rat.

In the present study, treatment with antipain, leupeptin and talopeptin significantly decreased the rate of zona loss from the rat blastocyst. Although the rates of zona loss of the thiolstatin-treated group and the $\alpha$-MAPI-treated groups were significantly less than that of the corresponding controls, it is reasonable to consider that this may result from a delay in embryonic growth rather than a direct thiolstatin- and $\alpha$-MAPI-inhibition of the removal of zona pellucida. Therefore, the inhibition of zona loss by antipain and leupeptin, although these are inhibitors of thiol proteinases as well as trypsin-like proteinases, must be the blockage of a trypsin-like proteinase instead of a thiol proteinase. Since talopeptin is a specific inhibitor of metal proteinases (Fukuhara, Murao, Nozawa \& Hatano, 1982), a metal proteinase may also function in the lysis of the rat blastocyst zona pellucida to the same degree as the trypsin-like proteinase. Serine proteinases maintain collagenase (a metal proteinase) activity in serum by suppressing serum collagenase inhibitors (Sakamoto, Goldhaber \& Glimcher, 1972); trypsin and chymotrypsin activate procollagenase to collagenase (Birkedal-Hansen, Cobb, Taylor \& Fullmer, 1976; Stricklin, Eisen, Bauer \& Jeffrey, 1978), and serine proteinases induce the secretion of collagenase from rabbit fibroblasts (Werb \& Aggeler, 1978). Therefore, the trypsin-like proteinase which appears to participate in zona lysis may act on the zona pellucida directly and/or indirectly by activating or facilitating metal proteinase activity.

Comparatively high doses of antipain, leupeptin and talopeptin were necessary to inhibit removal of the zona from the ovum. Furthermore, these inhibitors did not block removal completely. It is therefore likely that the active hatching mechanism may be the major cause of zona removal, and the proteinases may play only an auxiliary role in zona removal.

In the present study effects of proteinase inhibitors on the rat embryo were examined by an injection of the inhibitor solution in the uterine lumen of the rats. An injection of $20 \mu$ l of the vehicle fluids into the lumen caused delay in embryonic development and zona loss. In such a delicate system any substance added to the vehicle may change the pattern of development between the different groups of embryos simply by physicochemical effects on cell surfaces and the zona. The use of less toxic microbial proteinase inhibitors reduced this possibility, but further study is necessary before conclusive results can be obtained.

We thank Dr W. G. Wiest of Department of Obstetrics \& Gynecology, Washington University, St Louis, for editorial help in the preparation of the manuscript. 


\section{References}

Birkedal-Hansen, H., Cobb, C.M., Taylor, R.E. \& Fullmer, H.M. (1976) Activation of fibroblastprocollagenase by mast cell proteases. Biochim. Biophys. Acta 438, 273-286.

Dabich, D. \& Andary, T.J. (1974) Prevention of blastocyst implantation in mice with proteinase inhibitors. Fert. Steril. 25, 954-957.

Dabich, D. \& Andary, T.J. (1976) Tryptic- and chymotryptic-like proteinases in early and late preimplantation mouse blastocysts. Biochim. Biophys. Acta 444, $147-153$.

Denker, H.W. (1972) Blastocyst protease and implantation: effect of ovariectomy and progesterone substitution in the rabbit. Acta endocr., Copenh. 70, 591602.

Denker, H.W. (1977) Implantation: the role of proteinases, and blockage of implantation by proteinase inhibitors. Adv. Anat. Embryol. Cell Biol. 53, 1-123.

Fléchon, J.-E. \& Renard, J.-P. (1978) A scanning electron microscope study of the hatching of bovine blastocysts in vitro. J. Reprod. Fert. 53, 9-12.

Fukuhara, K., Murao, S., Nozawa, T. \& Hatano, M. (1982) Structural elucidation of talopeptin (MK-I), a novel metallo proteinase inhibitor produced by Streptomyces mozunensis MK-23. Tetrahedron Lett. 23, 2319-2322.

Gwatkin, R.B.L. (1964) Effect of enzymes and acidity on the zona pellucida of the mouse egg before and after fertilization. J. Reprod. Fert. 7, 99-105.

Hoversland, R.C. \& Weitlauf, H.M. (1978) The effect of estrogen and progesterone on the level of amidase activity in fluid flushed from the uteri of ovariectomized mice. Biol. Reprod. 19, 908-912.

Hoversland, R.C. \& Weitlauf, H.M. (1981) Lysis of the zona pellucida and attachment of embryos to the uterine epithelium in ovariectomized mice treated with oestradiol-17及 and progesterone. J. Reprod. Fert. 62, 111-116.

Ichikawa, S., Morioka, H., Ohta, M., Oda, K. \& Murao, S. (1983) Effect of various proteinase inhibitors on ovulation of explanted hamster ovaries. $J$. Reprod. Fert. 68, 407-412.

Ichikawa, S., Takehara, Y., Shibata, T., Tamada, H., Oda, K. \& Murao, S. (1984) Inhibition of in-vitro fertilization of hamster oocytes by a thiol proteinase inhibitor. J. Reprod. Fert. 72, 515-519.

Kane, M.T. (1983) Evidence that protease action is not specifically involved in the hatching of rabbit blastocysts caused by commercial bovine serum albumin in culture. J. Reprod. Fert. 68, 471-475.

Konwinski, M., Solter, D. \& Koprowski, H. (1978) Effect of removal of the zona pellucida on subsequent development of mouse blastocysts in vitro. J. Reprod. Fert. 54, 137-143.
Massip, A. \& Mulnard, J. (1980) Time-lapse cinematographic analysis of hatching of normal and frozenthawed cow blastocysts. J. Reprod. Fert. 58, 475-478.

Mazzei, D., Novi, C. \& Bazzi, C. (1966) Mitogenic action of trypsin and chymotrypsin. Lancet ii, 232.

McLaren, A. (1970) The fate of the zona pellucida in mice. J. Embryol. exp. Morph. 23, 1-19.

Mintz, B. (1962) Experimental study of the developing mammalian egg: removal of the zona pellucida. Science, N.Y. 138, 594-595.

Mintz, B. (1972) Implantation-initiating factor from mouse uterus. In Biology of Mammalian Fertilization and Implantation, pp. 343-356. Eds K. S. Moghissi \& E. S. E. Hafez. Charles C. Thomas, Springfield.

Morton, D.B. (1977) The occurrence and function of proteolytic enzymes in the reproductive tract of mammals. In Proteases in Mammalian Cell and Tissues, pp. 445-500. Ed. A. J. Barrett. North Holland Publ. Co., New York.

Owers, N.O. \& Blandau, R.J. (1968) Enzymatic activities of implanting guinea pig embryos. Anat. Rec. 160, 404, Abstr.

Pienkowski, M., Solter, D. \& Koprowski, H. (1974) Early mouse embryos: growth and differentiation in vitro. Expl Cell Res. 85, 424-428.

Pinsker, M.C., Sacco, A.G. \& Mintz, B. (1974) Implantation-associated proteinase in mouse uterine fluid. Devl Biol. 38, 285-290.

Rosenfeld, M.G. \& Joshi, M.S. (1981) Effect of a rat uterine fluid endopeptidase on lysis of the zona pellucida. J. Reprod. Fert. 62, 199-203.

Sakamoto, S., Goldhaber, P. \& Glimcher, M.J. (1972) Maintenance of mouse bone collagenase activity in the presence of serum protein by addition of trypsin. Proc. Soc. exp. Biol. Med. 139, 1038-1041.

Sameshima, H., Taya, K., Sasamoto, S. \& Etoh, T. (1982) Superovulation induced by a single pituitary transplanted beneath the kidney capsule in adult rats. $J$. Endocr. 94, 339-345.

Smithberg, M. (1953) The effect of different proteolytic enzymes on the zona pellucida of mouse ova. Anat. Rec. 117, 554. Abstr.

Stricklin, G. P., Eisen, A.Z., Bauer, E.A. \& Jefirey, J.J. (1978) Human skin fibroblast collagenase: chemical properties of precursor and active forms. Biochemistry, N.Y. 17, 2331-2337.

Werb, Z. \& Aggeler, J. (1978) Proteases induce secretion of collagenase and plasminogen activator by fibroblasts. Proc. natn. Acad. Sci. U.S.A. 75, 1839-1843.

Received 12 June 1984 